\title{
TGF- $\beta$-MTAI-SMAD7-SMAD3-SOX4-EZH2 Signaling Axis Promotes Viability, Migration, Invasion and EMT of Hepatocellular Carcinoma Cells
}

\author{
Kangjun Zhang' \\ Taishi Fang' \\ Yajie Shao ${ }^{2}$ \\ Yanhui $\mathrm{Wu}^{3}$
}

'Hepatic Surgery Department, The Third People's Hospital of Shenzhen, Shenzhen City, Guangdong Province, People's Republic of China; ${ }^{2}$ Department of Anesthesiology, Tongji Hospital, Tongji Medical College, Huazhong University of Science and Technology, Wuhan City, Hubei Province, People's Republic of China; ${ }^{3}$ Hepatic Surgery Center, Tongji Hospital, Tongii Medical College, Huazhong University of Science and Technology, Wuhan City, Hubei Province, People's Republic of China
Correspondence: Yanhui Wu Hepatic Surgery Center, Tongji Hospital, Tongji Medical College, Huazhong University of Science and Technology, No. I095 Jiefang Avenue, Qiaokou District, Wuhan City, Hubei Province, 430030,

People's Republic of China

Tel +86-027-83665313

Email Wuyanhai_yhiw@163.com
Introduction: Enhancer of zeste homolog 2 (EZH2) is implicated in hepatocellular carcinoma (HCC), but whether transforming growth factor- $\beta$ (TGF- $\beta$ )-metastasis associated 1 (MTA1)-SMAD7-SMAD3-SRY-Box Transcription Factor 4 (SOX4)-EZH2 signaling axis, in which EZH2 participates, is also involved in HCC remained unknown.

Methods: Data on EZH2 expression in liver hepatocellular carcinoma (LIHC) and its relation with prognosis of HCC patients were predicted and analyzed using online databases. Following transfection with or without TGF- $\beta 1$, HCC cell viability, migration and invasion were determined with MTT, Scratch and Transwell assays. Relative expressions of epithelialto-mesenchymal transition (EMT)-related factors (N-Cadherin, Vimentin, and E-Cadherin) and TGF- $\beta$-MTA1-SMAD7-SMAD3-SOX4-EZH2 signaling axis factors (TGF- $\beta$, MTA1, SMAD7, phosphorylated-SMAD3, SOX4 and EZH2) were calculated via reverse transcription-quantitative polymerase chain reaction (RT-qPCR) and Western blot.

Results: EZH2 was upregulated in HCC, which was related to poor prognosis. Silencing EZH2 suppressed EZH2 expression and HCC cell viability, migration, and invasion, and increased E-Cadherin expression yet decreased N-Cadherin and Vimentin expression, whereas EZH2 overexpression did conversely. Also, silencing EZH2 reversed the effects of TGF- $\beta 1$ on promoting viability, migration, and invasion, as well as N-Cadherin and Vimentin expressions, yet suppressing E-Cadherin expression in HCC cells. In addition, TGF- $\beta 1$ promoted TGF- $\beta$, MTA1, SOX4 and EZH2 expressions and p-SMAD3/SMAD3 ratio yet suppressed SMAD7, whereas silencing EZH2 solely reversed the effects of TGF- $\beta 1$ on EZH2 expression in HCC cells.

Conclusion: The present study provides a theoretical basis for TGF- $\beta$-MTA1-SMAD7SMAD3-SOX4-EZH2 signaling cascade in viability, migration, invasion, and EMT of HCC cells. Inhibiting these signals may represent a therapeutic pathway for the treatment of metastatic HCC.

Keywords: hepatocellular carcinoma, enhancer of zeste homolog 2, transforming growth factor- $\beta$, metastasis, metastasis associated 1-SMAD7-SMAD3-SRY-box transcription factor 4 axis, MTA1-SMAD7-SMAD3-SOX4 axis

\section{Introduction}

As the most prevalent form of liver cancer, hepatocellular carcinoma (HCC), at present, is not only a leading cause of cancer-associated death globally but also a highly aggressive disease with a poor prognosis. ${ }^{1,2} \mathrm{HCC}$ is also a complicated 
disease with a variety of pathogenic mechanisms caused by several risk factors, of which chronic hepatitis $\mathrm{B}$ virus (HBV) or hepatitis $\mathrm{C}$ virus (HCV) infection and chronic alcohol consumption have been underlined as those predominant, making it difficult to characterize within a single biomarker. ${ }^{3,4}$ From approximately 1995 until perhaps 5 years ago, radiofrequency ablation and subsequent microwave ablation have been the dominant percutaneous ablative technologies for the management of HCC. However, the location and number of tumors are critical and can be a limitation for the use of these technologies. ${ }^{5}$ Surgical operation has been suggested and considered as the only potentially curative strategy for patients with HCC nowadays; however, chances that patients will be eventually "cured" after resection remain poor and ill-defined. ${ }^{6}$ Although a number of consistent alterations to metabolic genes have been identified in $\mathrm{HCC}$, their prognostic values are inadequately discussed and need to be further elucidated in detail. ${ }^{7}$ Therefore, it has become urgently needed to further work out a viable therapeutic method and target for HCC.

As the main enzymatic catalytic polycomb repressive complex 2 (PRC2) subunit and one of the most important histone methyltransferases, enhancer of zeste homolog 2 (EZH2) has the capacity on alteration on downstream target gene expressions via Lys-27 trimethylation in histone 3 (H3K27me3) which is a transcriptionally repressive epigenetic mark regulating gene expression, differentiation and development, thus establishing and maintaining H3K27 trimethylation repressive marks. ${ }^{8,9}$ A previous study has identified the role of EZH2 in cell proliferation, apoptosis and senescence and the application of targeting EZH2 for cancer therapy. ${ }^{10}$ It has been uncovered that EZH2 is overexpressed and can be used as a therapeutic target for ovarian cancer. ${ }^{11}$ Also, EZH2 can act as one of the key driving oncogenes and be adopted as the biomarker for aggressive prostate cancer. ${ }^{12}$ In addition, EZH2 oncogenic deregulation has been indicated as a possible opportunity for targeted therapy for lung cancer. ${ }^{13}$ Furthermore, the implication and the promotive effects of EZH2 in HCC development and progression have been additionally discovered. ${ }^{14}$ Previous studies have also shown that EZH2 could modulate transforming growth factor- $\beta$ (TGF- $\beta$ ) pathway in HCC, and the implication of TGF- $\beta$-Metastasis Associated 1 (MTA1)-SRY-Box Transcription Factor 4 (SOX4)-EZH2 signaling axis in tumor metastasis and epithelial-to-mesenchymal transition (EMT). ${ }^{15,16}$ Nevertheless, whether TGF- $\beta$-MTA1-
SMAD7-SMAD3-SOX4-EZH2 signaling axis was involved in HCC awaited to be further elucidated. Therefore, we aimed to discover and discuss the detailed role of EZH2 and the possible participation of TGF- $\beta$ MTA1-SMAD7-SMAD3-SOX4-EZH2 signaling axis in HCC cells, hoping to work out a viable therapy for HCC in the future.

\section{Materials and Methods Ethical Statement}

The current study has been approved by the ethics committee of The Third People's Hospital of Shenzhen (serial number: NK2017090101), and also obtained the written informed consents from recruited patients who agreed the usage of their tissue in our study. This study was conducted in accordance with the Declaration of Helsinki. ${ }^{17}$

\section{Bioinformatic and Survival Analysis}

To determine the role of EZH2 played in HCC, data on EZH2 expression in liver hepatocellular carcinoma (LIHC) was collected from gene expression profiling interactive analysis 2 (GEPIA 2, http://gepia2.cancer-pku.cn/ \#analysis).

In order to assess and evaluate EZH2 expression in HCC patients, patients were assigned to high or low EZH2 groups, and their survival rates were predicted using Kaplan-Meier Plotter (http://kmplot.com/analysis/index. php), and monitored and determined every 10 months. Survival analysis was plotted via Kaplan-Meier Curve.

\section{Clinical Samples}

Clinical samples used for our current study were collected from tissues of patients with HCC and normal healthy patients in The Third People's Hospital of Shenzhen from 2017 September to 2019 August ( $\mathrm{n}=70$ for each). All patients enrolled were conformed to the criteria: (a) no pre-surgery chemotherapy or radiotherapy; (b) no other cancers, autoimmune diseases, or infectious diseases, and so on. All tissue samples were carefully collected during surgery and were washed with phosphate buffered saline (PBS, P1022, Solarbio, Beijing, China) followed by being stored in $-80^{\circ} \mathrm{C}$ refrigerator for subsequent analysis. Meanwhile, we also collected and summarized the basic characteristics of patients, including sex, age, tumor size, hepatitis B virus (HBV), hepatitis C virus (HCV), alcohol consumption, serum alpha-fetoprotein (AFP) level, Number (No.) of tumor nodules, Cirrhosis; Venus 
infiltration, Edmondson-Steiner grading, and tumor-nodemetastasis (TNM) stage, which are detailed in Table 1. The patients were assigned to high- or low-EZH2 expression groups in accordance with the median of the RNA expression level of EZH2.

\section{Cell Culture and Treatment}

Human liver epithelial cell-line THLE-2 (BNCC322618), and HCC cell line (SNU-182, BNCC353594; SUN-387, BNCC253492; SNU-423, BNCC234890; and PLC/PRF/5, BNCC293647) were ordered from BeiNa Bio (Beijing, China). THLE-2 cells were grown in RPMI-1640 medium (90022, Solarbio, China) with $10 \%$ fetal bovine serum (FBS, F2442, Sigma-Aldrich, St. Louis, MO, USA), and SNU-182, SUN-387, and SNU-423 cells were maintained in RPMI-1640 medium with 10\% FBS, $20 \mathrm{mmol} / \mathrm{L}$ 4- (2hydroxyethyl)-1-piperazineethanesulfonic acid (HEPES, H4034, Sigma-Aldrich, USA), $2 \mathrm{~g} / \mathrm{mL}$ sodium bicarbonate (S5761, Sigma-Aldrich, USA) and $100 \mathrm{U} / \mathrm{mL}-100 \mathrm{mg} / \mathrm{mL}$ penicillin-streptomycin (P4333, Sigma-Aldrich, USA). In addition, PLC/PRF/5 cells were cultured in Dulbecco's modified Eagle's medium (DMEM, 90113, Solarbio, China) with $10 \%$ FBS and $1 \%$ penicillin-streptomycin. All the cells were cultured at $37^{\circ} \mathrm{C}$ with $5 \% \mathrm{CO}_{2}$. As EZH2 expression was highest in $\mathrm{PLC} / \mathrm{PRF} / 5$ cells, these two cells were used for our studies. Also, TGF- $\beta 1$ (T1654) was obtained from Sigma-Aldrich and was added into HCC PLC/PRF/5 cells at a concentration of $5 \mathrm{ng} / \mathrm{mL}$ for 24 hours as confirmed in a previous study. ${ }^{18}$

\section{Transfection}

Short hairpin RNA targeting EZH2 (shEZH2) was purchased from Gene Pharma (Shanghai, China). EZH2 overexpression was made with pcDNA 3.1 plasmid (VT1001, Youbio, Changsha, China), and the controls for both shEZH2 and EZH2 (Vector) were additionally obtained from Gene Pharma. For transfection, $1 \times 10^{6}$ cells/well HCC cells were cultured in 6-well plates and when they became $90 \%$ confluence, transfection was performed at room temperature (RT) using Lipofectamine 2000 reagent (11668-030, Invitrogen, Carlsbad, CA, USA). Sequence for transfection is provided in Table 2.

\section{MTT Assay}

$5 \times 10^{3}$ cells/well treated or transfected $\mathrm{HCC}$ cells were cultured in 96-well plates at $37^{\circ} \mathrm{C}, 5 \% \mathrm{CO}_{2}$ for 0,24 and 48 hours. $10 \mu \mathrm{L}$ MTT reagent (C0009S, Beyotime, Shanghai, China) was added into each well at $37^{\circ} \mathrm{C}$ for
Table I Basic Characteristics of Patients

\begin{tabular}{|c|c|c|c|}
\hline \multirow[t]{2}{*}{ Characteristics } & \multicolumn{2}{|c|}{ EZH2 Expression } & \multirow[t]{2}{*}{$P$ value } \\
\hline & $\begin{array}{l}\text { Low } \\
(n=35)\end{array}$ & $\begin{array}{l}\text { High } \\
(n=35)\end{array}$ & \\
\hline $\begin{array}{l}\text { Sex } \\
\text { male } \\
\text { Female }\end{array}$ & $\begin{array}{l}23 \\
12\end{array}$ & $\begin{array}{l}25 \\
10\end{array}$ & 0.607 \\
\hline $\begin{array}{l}\text { Age }(y) \\
\quad<50 \\
\quad \geq 50\end{array}$ & $\begin{array}{l}15 \\
20\end{array}$ & $\begin{array}{l}11 \\
24\end{array}$ & 0.322 \\
\hline $\begin{array}{l}\mathrm{HCV} \\
\text { No } \\
\text { Yes }\end{array}$ & $\begin{array}{l}32 \\
3\end{array}$ & $\begin{array}{l}34 \\
\text { I }\end{array}$ & 0.614 \\
\hline $\begin{array}{l}\text { Alcohol consumption } \\
\text { No } \\
\text { Yes }\end{array}$ & $\begin{array}{l}16 \\
19\end{array}$ & $\begin{array}{l}14 \\
21\end{array}$ & 0.629 \\
\hline $\begin{array}{l}\text { Tumor size }(\mathrm{cm}) \\
\quad \leq 4 \\
>4\end{array}$ & $\begin{array}{l}19 \\
16\end{array}$ & $\begin{array}{l}8 \\
27\end{array}$ & 0.007 \\
\hline $\begin{array}{l}\text { HBV } \\
\text { Absent } \\
\text { Present }\end{array}$ & $\begin{array}{l}16 \\
19\end{array}$ & $\begin{array}{l}13 \\
22\end{array}$ & 0.467 \\
\hline $\begin{array}{l}\text { Serum AFP level }(\mathrm{ng} / \mathrm{mL}) \\
\quad<20 \\
\quad \geq 20\end{array}$ & $\begin{array}{l}17 \\
18\end{array}$ & $\begin{array}{l}14 \\
21\end{array}$ & 0.470 \\
\hline $\begin{array}{l}\text { No. of tumor nodules } \\
\quad \text { । } \\
\geq 2\end{array}$ & $\begin{array}{l}22 \\
13\end{array}$ & $\begin{array}{l}26 \\
9\end{array}$ & 0.303 \\
\hline $\begin{array}{l}\text { Cirrhosis } \\
\text { Absent } \\
\text { Present }\end{array}$ & $\begin{array}{l}18 \\
17\end{array}$ & $\begin{array}{l}14 \\
21\end{array}$ & 0.337 \\
\hline $\begin{array}{l}\text { Venous infiltration } \\
\text { Absent } \\
\text { Present }\end{array}$ & $\begin{array}{l}25 \\
10\end{array}$ & $\begin{array}{l}20 \\
15\end{array}$ & 0.212 \\
\hline $\begin{array}{l}\text { Edmondson-Steiner grading } \\
\text { I-II } \\
\text { III-IV }\end{array}$ & $\begin{array}{l}27 \\
8\end{array}$ & $\begin{array}{l}16 \\
19\end{array}$ & 0.007 \\
\hline $\begin{array}{l}\text { TNM stage } \\
\text { I-II } \\
\text { III-IV }\end{array}$ & $\begin{array}{l}24 \\
11\end{array}$ & $\begin{array}{l}13 \\
22\end{array}$ & 0.008 \\
\hline
\end{tabular}

Abbreviations: HBV, hepatitis B virus; AFP, alpha-fetoprotein; TNM, tumor-nodemetastasis; $\mathrm{HCV}$, hepatitis $C$ virus.

another 4 hours. OD value was recorded using iMark microplate reader (Bio-Rad, Hercules, CA, USA) at an absorbance of $570 \mathrm{~nm}$. 
Table 2 Sequences for Transfection

\begin{tabular}{|l|l|}
\hline Gene & Sequence $\left(\mathbf{5}^{\prime}\right.$ '->-3') \\
\hline $\begin{array}{l}\text { shEZH2 sense } \\
\text { obligo }\end{array}$ & $\begin{array}{l}\text { CCGGGTTGGAGACTGCTGGTTTAAACTCG } \\
\text { AGTTTAAACCAGCAGTCTCCAACTTTTTG }\end{array}$ \\
\hline $\begin{array}{l}\text { shEZH2 antisense } \\
\text { obligo }\end{array}$ & $\begin{array}{l}\text { AATTCAAAAAGTTGGAGACTGCTGGTTTA } \\
\text { AACTCGAGTTTAAACCAGCAGTCTCCAAC }\end{array}$ \\
\hline
\end{tabular}

\section{Scratch Assay}

$1 \times 10^{5}$ cells/well transfected or treated HCC cells were grown in a 6-well plate, and after cells reached approximately $80 \%$ confluence, an artificial scratch was made using a sterile pipette tip. $\mathrm{HCC}$ cells were further cultured in a serum-free medium at $37^{\circ} \mathrm{C}, 5 \% \mathrm{CO}_{2}$. Cell images were observed, and photos were taken in an inverted optical microscope (GX71, Olympus, Tokyo, Japan) at 0 and 24 hours under $\times 100$ magnification.

\section{Transwell Assay}

$1 \times 10^{5}$ cells/well treated or transfected HCC cells with $200 \mu \mathrm{L}$ non-serum medium were transferred to Transwell chambers of $8-\mu \mathrm{m}$ pore (CLS-3464, Sigma-Aldrich, USA) which have been pre-coated with Matrigel (356237, Corning, Inc., Corning, NY, USA) at $37^{\circ} \mathrm{C}$ with $5 \% \mathrm{CO}_{2}$, and $600 \mu \mathrm{L}$ complete medium was added into corresponding lower Transwell chamber. 24 hours later, all invaded cells were fixed in Methanol (322415, Sigma-Aldrich, USA) and stained using 0.1\% Giemsa (C0133, Beyotime, China). All cells were calculated in five randomly picked fields, and photos were taken in an inverted optical microscope under $\times 250$ magnification.

\section{RNA Isolation and Reverse Transcription- Quantitative Polymerase Chain Reaction (RT-qPCR)}

Trizol (T9424, Sigma-Aldrich, USA) was used for total RNA extraction of treated or transfected HCC cells and tissues. All RNA extracted was subsequently preserved in $-80^{\circ} \mathrm{C}$. A NanoDrop Lite spectrophotometer (ND-LITE, Thermo Fisher Scientific, Waltham, MA, USA) was used for concentration determination. CDNA was then synthesized via a first strand cDNA synthesis kit (D7178S, Beyotime, China), and RT-qPCR was conducted by RTqPCR kit (D7277S, Beyotime, China) and operated in Touch real-time PCR system (CFX86, Bio-Rad, USA) under the conditions: 10 minutes at $95^{\circ} \mathrm{C}$, followed by
40 cycles of 15 seconds at $95^{\circ} \mathrm{C}$ and 1 minute at $62^{\circ} \mathrm{C}$. Relative expressions were calculated using the $2^{-\Delta \Delta C T}$ method, in which GAPDH was used as an internal reference. ${ }^{19}$ Primer sequences are referred to in Table 3.

\section{Western Blot}

Relative protein expressions of migration and invasionrelated (N-Cadherin, Vimentin, and E-Cadherin) and TGF- $\beta 1$-MTA1-SMAD7-SMAD3-SOX4-EZH2 signaling axis-related factors (TGF- $\beta$; MTA1; SMAD7; phosphorylated-SMAD3, p-SMAD3; SMAD3; SOX4; and EZH2) were measured via Western blot as previously described. ${ }^{16}$ Total protein was lysed and extracted with RIPA buffer (P0013C, Beyotime, China) after treated or transfected HCC cell collection, and the concentration of protein was measured with bicinchoninic acid (BCA) protein reagent (P0012S, Beyotime, China). $30 \mu \mathrm{g}$ sample protein lysates were electrophoresed with sodium dodecyl sulfate-polyacrylamide gel electrophoresis (SDS-PAGE) (P0012A, Beyotime, China), and transferred into polyvinylidene fluoride (PVDF) membrane (FFP33, Beyotime, China) blocked with fat-free milk (5\%) for 2 hours and incubated in indicated primary antibodies, including those against N-Cadherin (ab18203, 1:2000, $130 \mathrm{kDa}$ ), Vimentin (ab92547, 1:5000, $54 \mathrm{kDa}$ ), E-Cadherin (ab231303, 1:2000, 97

Table 3 Primers for RT-qPCR

\begin{tabular}{|c|c|}
\hline Gene & Primers $\left(5^{\prime}->-3^{\prime}\right)$ \\
\hline \multicolumn{2}{|l|}{$\mathrm{EZH} 2$} \\
\hline Forward & GAAGTTTTAGATCAGGATGG \\
\hline Reverse & TGTCTAGAGCTGTTTCTGTG \\
\hline \multicolumn{2}{|c|}{ N-Cadherin } \\
\hline Forward & GCTGGTATCTATGAAGTTCC \\
\hline Reverse & TAGGTGTAAGCTCTCTATGG \\
\hline \multicolumn{2}{|l|}{ Vimentin } \\
\hline Forward & CTTAAAGGAACCAATGAGTC \\
\hline Reverse & GAGAAGTTTCGTTGATAACC \\
\hline \multicolumn{2}{|c|}{ E-Cadherin } \\
\hline Forward & GATGATGTGAACACCTACAA \\
\hline Reverse & GTAGCTATGATTAGGGCTGT \\
\hline \multicolumn{2}{|l|}{ GAPDH } \\
\hline Forward & TTTTTGGTTTTAGGGTTAGTTAGTA \\
\hline Reverse & AАAАССТССТАТААТАТСССТССТС \\
\hline
\end{tabular}


kDa), TGF- $\beta$ (ab215715, 1:1000, 44 kDa), MTA1 (ab71153, 1:2000, $81 \mathrm{kDa}$ ), SMAD7 (ab90086, 1:500, $46 \mathrm{kDa}$ ), p-SMAD3 (ab52903, 1:2000, $48 \mathrm{kDa}$ ), SMAD3 (ab40854, 1:2000, $55 \mathrm{kDa}$ ), SOX4 (ab70598, 1:2000, $48 \mathrm{kDa})$ and EZH2 (ab191080, 1:500, $93 \mathrm{kDa})$ at $4{ }^{\circ} \mathrm{C}$ overnight, and the membrane was also incubated with primary antibodies against internal control GAPDH (ab8245, 1:2000, $36 \mathrm{kDa}$ ) at $4^{\circ} \mathrm{C}$ overnight. The membrane was incubated in horseradish peroxidase (HRP)conjugated secondary antibodies: goat anti-rabbit IgG H\&L (ab205718, 1:2000) and goat anti-mouse IgG H\&L (ab205719, 1:2000) for an hour at RT and washed using tris-buffer saline tween (TBST, T1085, Solarbio, China) for three times. All primary and secondary antibodies were ordered from Abcam (Cambridge, UK).

Enhanced chemiluminescence (ECL) reagent (P0018S, Beyotime, China) was finally used for visualization after protein band collection. Data were analyzed with iBright CL750 Imaging System (A44116, Thermo Fisher Scientific, USA) and grey values were calculated via ImageJ (ver. 5.0, Bio-Rad, USA).

\section{Statistical Analysis}

Each experiment was repeated over three times in an independent manner. Data were expressed as mean \pm standard deviation (SD). Survival rates of HCC patients were analyzed using Kaplan-Meier Curve. GraphPad 8.0 (GraphPad, Inc., La Jolla, CA, USA) and SPSS 20.0 (SPSS, Chicago, IL, USA) were both used for statistical analysis. Statistical significance was determined by oneway ANOVA followed by Dunnett or Tukey's post hoc test and paired $t$ test. Statistical significance was determined when $P<0.05$.

\section{Results}

\section{EZH2 Was Upregulated in HCC, Which Was Related to Poor Prognosis of Patients}

To determine the role of EZH2 played in $\mathrm{HCC}$, data on EZH2 expression in LIHC was firstly collected from GEPIA 2, which showed an upregulated EZH2 expression in LIHC (Figure 1A, $P<0.05$ ). Also, results from Kaplan-Meier Plotter showed that high EZH2 expression was related to poor survival rate of HCC patients (Figure 1B). In addition, our data on patients with HCC presented that high EZH2 expression was significantly associated with tumor size, Edmondson-Steiner grading and TNM tumor stage (Table 1). Furthermore, we discovered that EZH2 expression was increased in both HCC tissue and cells, with highest expression in $\mathrm{PLC} / \mathrm{PRF} / 5$ cells (Figure $1 \mathrm{C}$ and $\mathrm{D}, \quad P<0.001$ ). Therefore, PLC/PRF/5 cells were used for subsequent studies.

\section{EZH2 Regulated EZH2 Expression and Cell Viability, Migration and Invasion and Epithelial-to-Mesenchymal Transition (EMT)-Related Markers in HCC Cells}

Then, we transfected shEZH2 and EZH2 overexpression plasmid into $\mathrm{HCC}$ cells to further determine the role and effect of EZH2 played in HCC, and silencing EZH2 suppressed EZH2 expression and cell viability at 24 and 48 hours in HCC cells (Figure 2A-D, $P<0.05$ ). Also, results from Scratch assay showed that silencing EZH2 inhibited HCC cell migration (Figure 2E and F, $P<0.001)$. However, overexpressed EZH2 promoted EZH2 expression and cell viability and migration in HCC cells (Figure 2A-F, $P<0.001$ ). Furthermore, according to the results of Transwell assay, silencing EZH2 suppressed, whereas EZH2 overexpression promoted HCC cell invasion (Figure $3 \mathrm{~A}$ and $\mathrm{B}, P<0.001$ ). As decreased E-cadherin and increased Vimentin/N-cadherin expression are conventional EMT markers, we subsequently measured their expressions in transfected HCC cells and silencing EZH2 in HCC cells suppressed $\mathrm{N}-\mathrm{Cadherin}$ and Vimentin yet promoted E-Cadherin, whereas EZH2 overexpression led to dropped E-Cadherin yet raised $\mathrm{N}$-Cadherin and Vimentin in HCC cells (Figure 3C-E, $P<0.05$ ).

\section{Silencing EZH2 Reversed the Effects of TGF- $\beta$ I on Viability, Migration and Invasion in HCC Cells}

We also transfected shEZH2 and treated the cells with TGF- $\beta 1$ to detect the effects of EZH 2 and TGF- $\beta 1$ on HCC cells. It was discovered from the results of MTT assay and Scratch assay that TGF- $\beta 1$ had a promotive effect on cell viability at 24 and 48 hours and cell migration, whereas silencing EZH2 reversed the promotive effects of TGF- $\beta 1$ (Figure $4 \mathrm{~A}-\mathrm{C}, \quad P<0.05$ ). Meanwhile, in the results of Transwell assay, TGF- $\beta 1$ promoted cell invasion, while silencing EZH2 reversed the effects of TGF- $\beta 1$ (Figure $5 \mathrm{~A}$ and $\mathrm{B}, P<0.05$ ). 

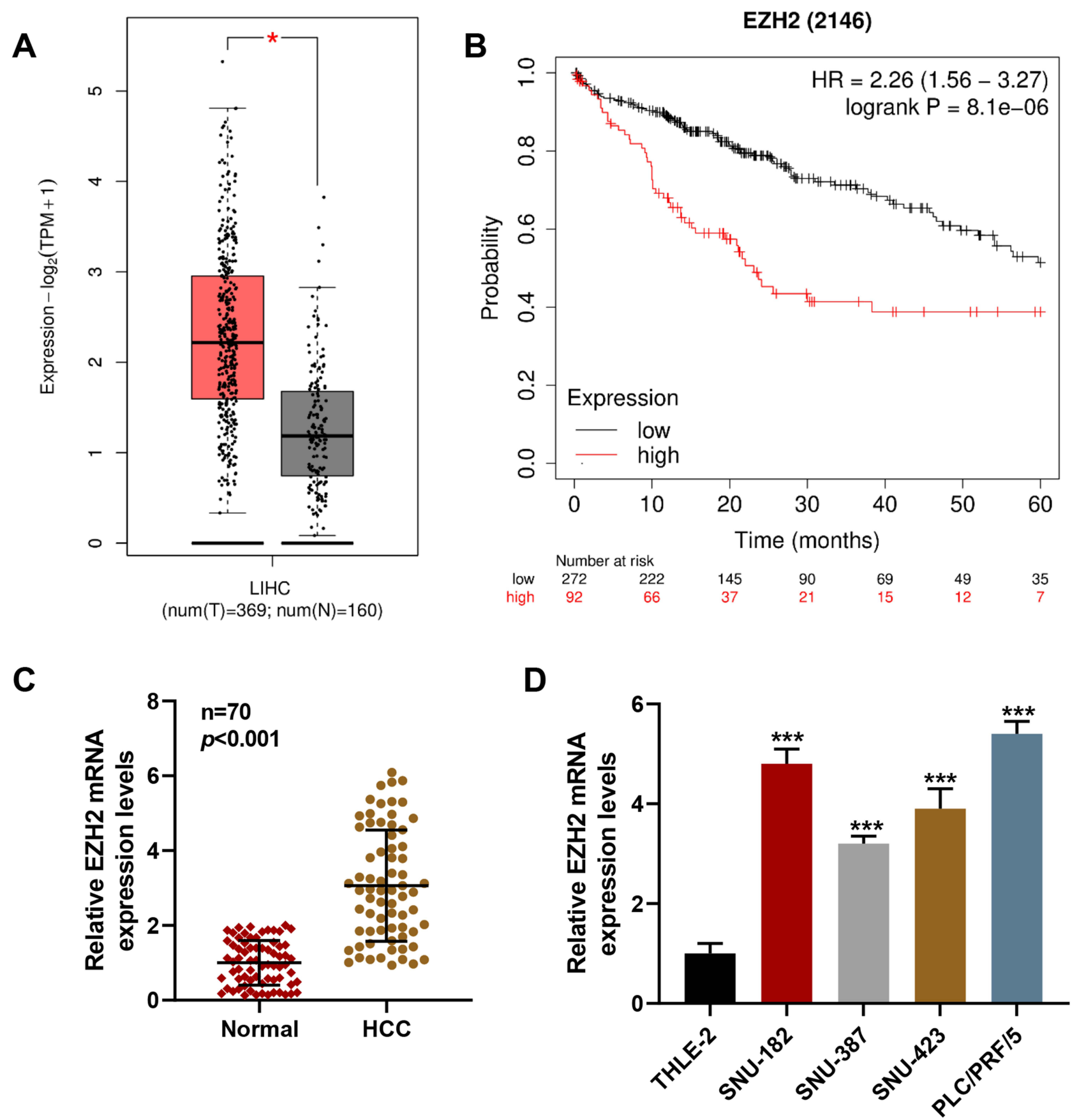

Figure I EZH2 was upregulated in HCC, which was associated with poor prognosis of patients. (A) Data on EZH2 expression in LIHC were collected from GEPIA 2 (http://gepia2.cancer-pku.cn/\#analysis). (B) Survival probability of patients with HCC was predicted using Kaplan-Meier Plotter (http://kmplot.com/analysis/index.php). (C) Relative EZH2 expression in HCC and Normal tissue was measured via RT-qPCR. GAPDH was used as internal control. (D) Relative EZH2 expression in HCC cells (SNU182, SNU-387, SNU-423, and PLC/PRF/5) and liver epithelial cell line THLE-2 was quantified via RT-qPCR. GAPDH was used as internal control. All experiments have been performed in triplicate and data were expressed as mean \pm standard deviation (SD). (A) $* P<0.00$ I, vs Non-LIHC (N); (D) $* * * P<0.00$ I, vs.

Abbreviations: THLE-2. EZH2, enhancer of zeste homolog 2; LIHC, liver hepatocellular carcinoma; GEPIA 2, gene expression profiling interactive analysis 2; HCC, hepatocellular carcinoma; RT-qPCR, quantitative real-time polymerase chain reaction.

Furthermore, based on results, TGF- $\beta 1$ resulted in increased $\mathrm{N}$-Cadherin and Vimentin yet decreased E-Cadherin (Figure 5C-E, $P<0.05$ ). However, silencing
EZH2 reversed the effects of TGF- $\beta 1$ on promoting $\mathrm{N}-\mathrm{Cadherin}$ and Vimentin yet suppressing E-Cadherin in $\mathrm{HCC}$ cells (Figure 5C-E, $P<0.01$ ). 
Silencing EZH2 Solely Reversed Effects of TGF- $\beta$ I on EZH 2 Expression in TGF- $\beta$ MTAI-SMAD7-SMAD3-SOX4-EZH2 Signaling Axis in HCC Cells

To further detect the mechanism, we measured expressions of proteins related to TGF- $\beta$-MTA1-SMAD7-SMAD3-
SOX4-EZH2 signaling axis in HCC cells following TGF$\beta 1$ and silencing EZH2. It was found that TGF- $\beta 1$ promoted TGF- $\beta$, MTA1, SOX4 and EZH2 expression and p-SMAD3/SMAD3 ratio yet suppressed SMAD7, however, silencing EZH2 solely reversed the effects of TGF$\beta 1$ on EZH2 expression in HCC cells, while it had no effects on TGF- $\beta$, MTA1, SMAD7 and SOX4 expressions,
A

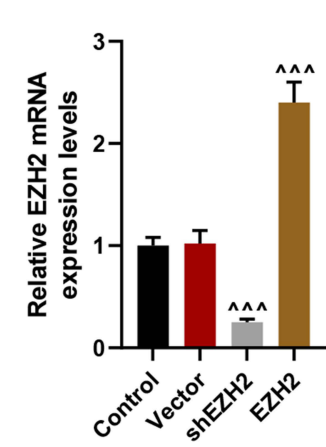

D

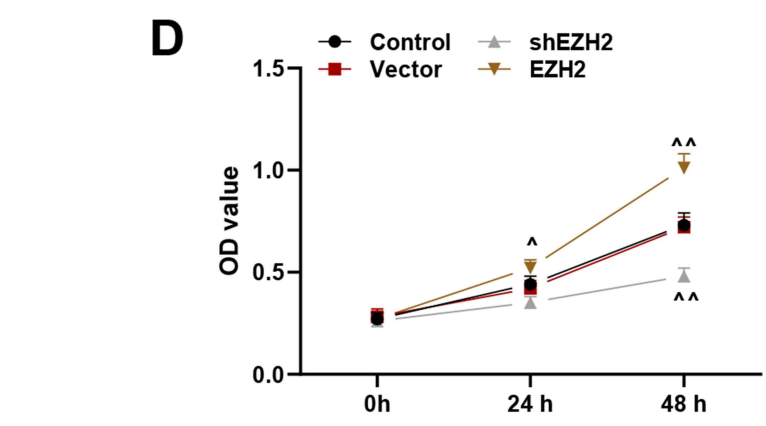

B

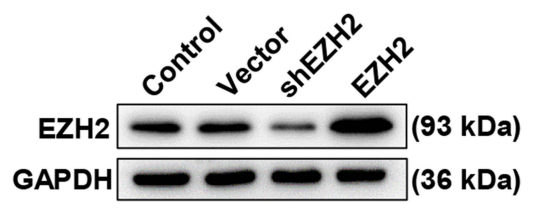

C

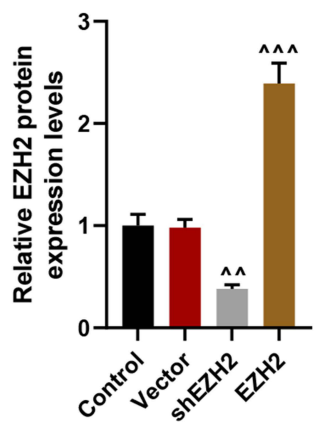

F
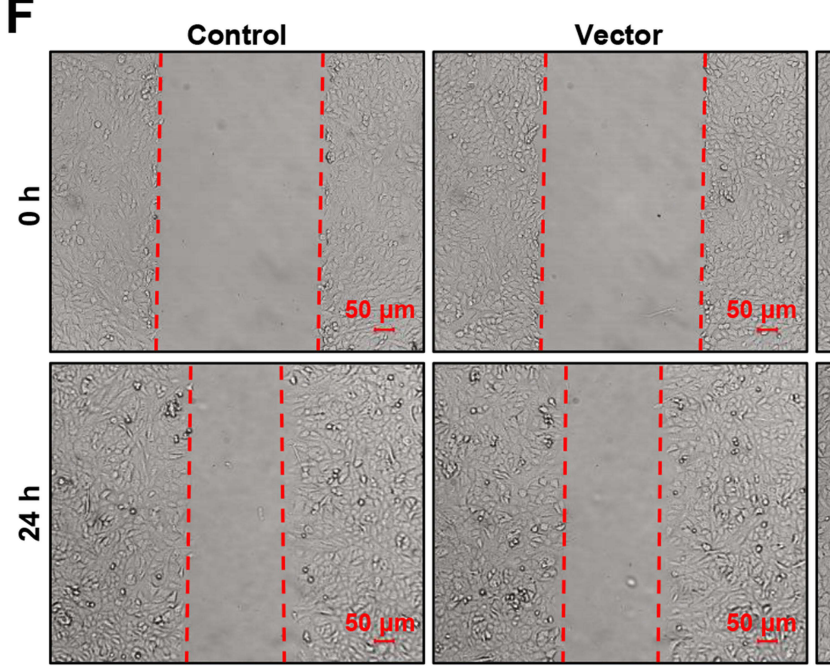

E

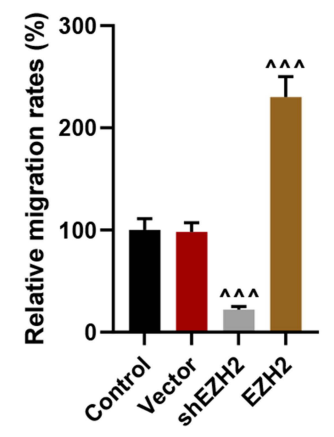

shEZH2
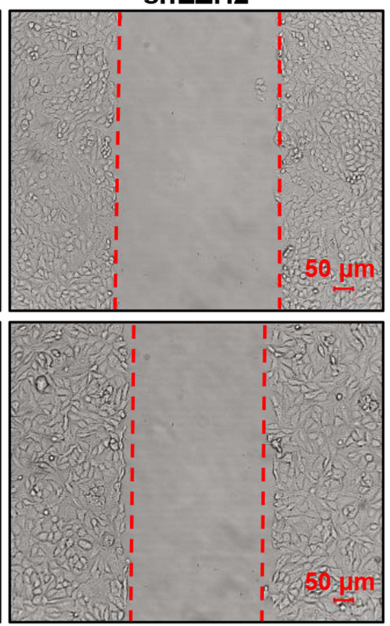

EZH2

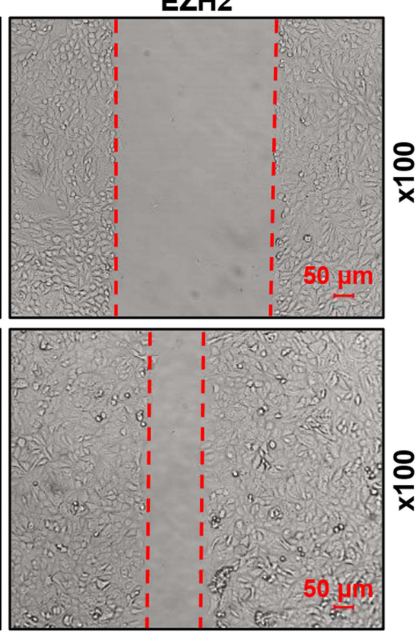

Figure 2 Silencing EZH2 suppressed EZH2 expression and HCC cell viability and migration, whereas EZH2 overexpression did conversely. (A) Relative EZH2 mRNA expression following shEZH2 or EZH2 overexpression plasmid transfection in HCC cell was calculated via RT-qPCR. GAPDH was chosen as internal reference. (B and C) Relative EZH2 protein expression following shEZH2 or EZH2 overexpression plasmid transfection in HCC cell was calculated via Western blot. GAPDH was chosen as internal reference. (D) MTT assay was used to determine the viability of $\mathrm{HCC}$ cells following shEZH2 or EZH2 overexpression plasmid transfection at 0,24 and 48 hours. (E and F) Scratch assay were used to detect the migration of $\mathrm{HCC}$ cells at 0 and 24 hours following shEZH 2 or EZH 2 overexpression plasmid transfection. Magnification: $\times$ 100. All experiments have been performed in independent triplicate and data were expressed as mean \pm standard deviation $(\mathrm{SD})$. ${ }^{\wedge} \mathrm{P}<0.05$, ${ }^{\wedge \wedge} \mathrm{P}<0.0 \mathrm{I}$, ${ }^{\wedge \wedge} \mathrm{P}<0.00 \mathrm{I}, \mathrm{vs}$ Vector. Abbreviation: shRNA, short hairpin RNA. 
as well as p-SMAD3/SMAD3 ratios (Figure 6A-C, $P<0.01)$. All the results further verified the TGF- $\beta$ MTA1- SMAD7-SMAD3-SOX4-EZH2 signaling cascade in HCC cells (Figure 7).

\section{Discussion}

For those large and diverse families, which have epigenetically repressed effects on transcription of key developmental genes, the polycomb group (PcG) proteins are those which help maintenance on gene-expression pattern of cells set in early development via regulation of chromatin structure, of which PRC2 has been identified as one of the main PcG complexes. ${ }^{20,21}$ EZH2, additionally, has been recognized as those genes encoding proteins, which comprise the core components of PRC2. ${ }^{22}$ Increasing evidence has addressed the role of $\mathrm{EZH} 2$ in different human malignancies, including ovarian cancer, prostate cancer, lung cancer and even HCC. ${ }^{11-14}$ in our study, we provided another evidence of EZH2 on HCC and its interaction with TGF- $\beta$-MTA1-SMAD7-SMAD3-SOX4-EZH2 signaling axis in HCC cells. To begin with, we discovered that EZH2 was upregulated in $\mathrm{HCC}$, which was related to poor prognosis. We also found that EZH2 overexpression promoted HCC cell viability, migration and invasion, with upregulated N-Cadherin and Vimentin yet downregulated E-Cadherin, while silencing EZH2 did conversely. In

A

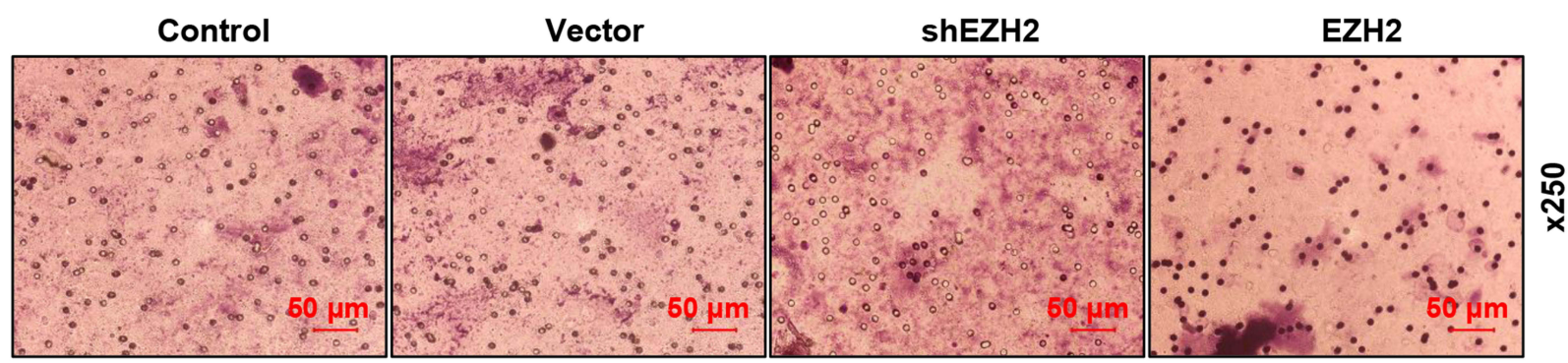

B
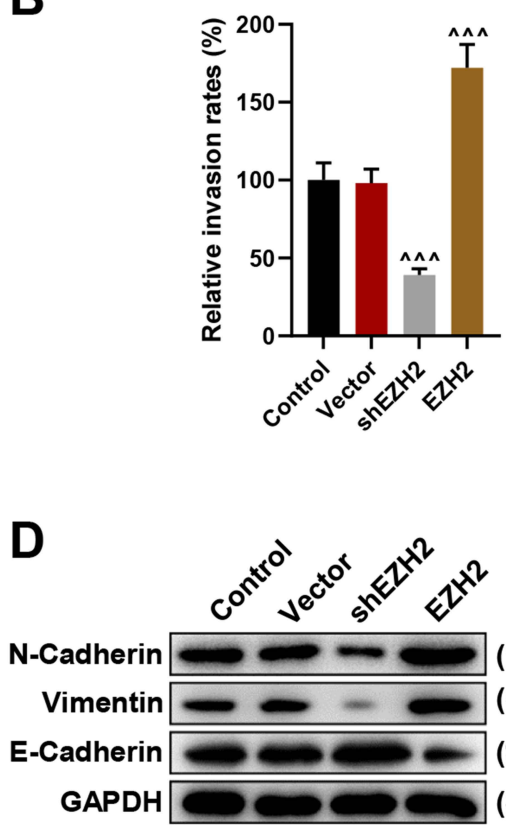

$(130 \mathrm{kDa})$

(64 kDa)

(97 kDa)

(36 kDa)
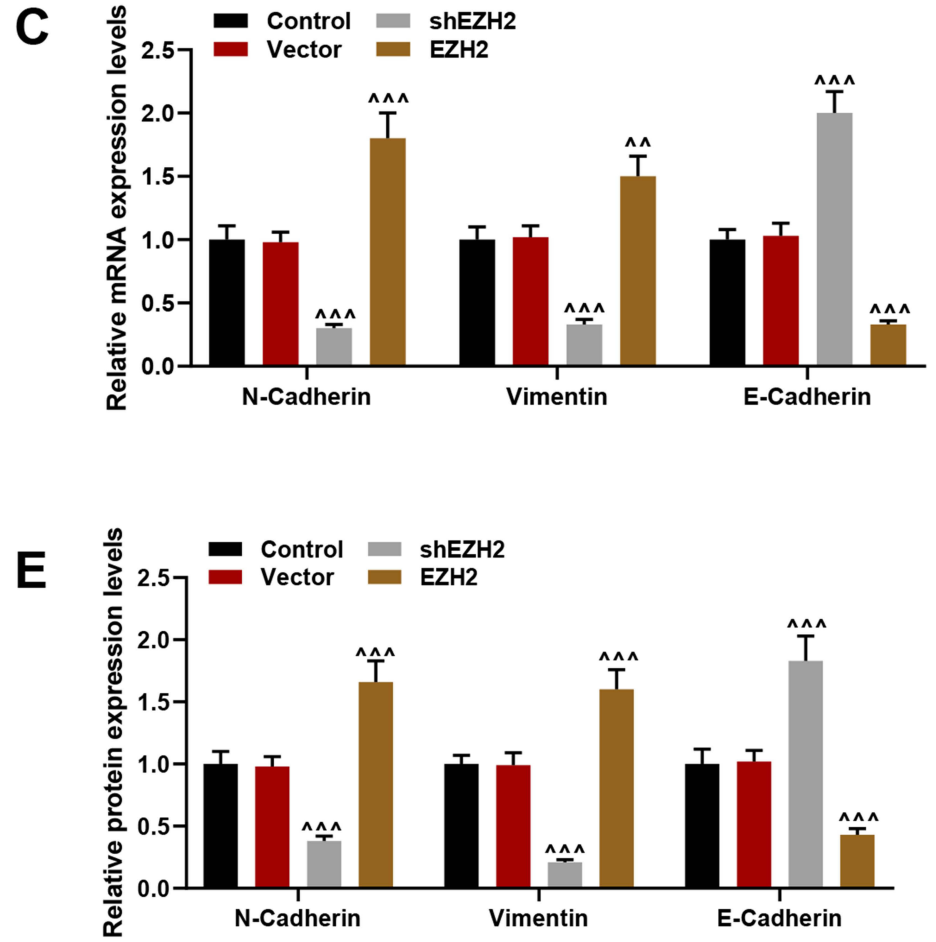

Figure 3 Silencing EZH2 suppressed HCC cell invasion and regulated and epithelial-to-mesenchymal transition (EMT)-related markers' expression, whereas EZH2 overexpression did oppositely. (A and $\mathbf{B}$ ) Transwell assay were used to detect the invasion of $\mathrm{HCC}$ cells at 24 hours following shEZH2 or EZH2 overexpression plasmid transfection. Magnification: $\times 250$. (C) Relative mRNA expression of EMT-related factors (N-Cadherin, Vimentin and E-Cadherin) in HCC cells following shEZH2 or EZH2 overexpression plasmid transfection was quantified using RT-qPCR. GAPDH was used as internal reference. (D and E) Relative mRNA expression of EMT-related factors (NCadherin, Vimentin and E-Cadherin) in HCC cells following shEZH2 or EZH2 overexpression plasmid transfection was quantified using RT-qPCR. GAPDH was used as internal reference. All experiments have been performed in independent triplicate and data were expressed as mean \pm standard deviation $(S D)$. ${ }^{\wedge} P<0.0 \mathrm{I}$, ${ }^{\wedge \wedge} P<0.00 \mathrm{I}$, vs Vector. 
addition, it was discovered that silencing EZH2 reversed the effects of TGF- $\beta 1$ in HCC cells. Furthermore, to the best of our knowledge, we firstly put forward that TGF- $\beta$ MTA1-SMAD7-SMAD3-SOX4-EZH2 signaling axis was implicated in HCC in vitro via promoting HCC cell viability, migration, invasion and EMT process.

Cancer cell proliferation is essential in cancer development, as manifested and demonstrated by altered expressions and/or activities of cell cycle-associated proteins. ${ }^{23}$ Metastasis of cancer, as defined, is the dissemination of cancer cell from tumor sites to the succeeding new colonies seeding in distant tissues, and a multistep process, known as the invasion-metastasis cascade, has also been found to have an implication. ${ }^{24}$ As a developmental program, EMT has a critical function in metastasis, and in the process of metastatic progression, some modifications both genetic and epigenetic can endow malignant cells with the properties that have effects on modulation of metastatic capacity. ${ }^{25,26}$ E-Cadherin, N-Cadherin, and Vimentin are those EMTrelated factors. ${ }^{27}$ As two members of the Cadherin family, E-Cadherin and N-Cadherin are the most prominent cell adhesion molecules, and E-Cadherin is a glycoprotein with transmembrane ability, which is pivotal to cell-to-cell adhesion and acts as tumor-suppressor, while N-Cadherin, on the opposite confers malignant cells upon metastasis acquisition or promotion. ${ }^{28,29}$ In addition, Vimentin, an intermediate filament protein that is upregulated characteristically in those cells with EMT, has been regarded as an EMT marker as well. ${ }^{30}$ It has
A

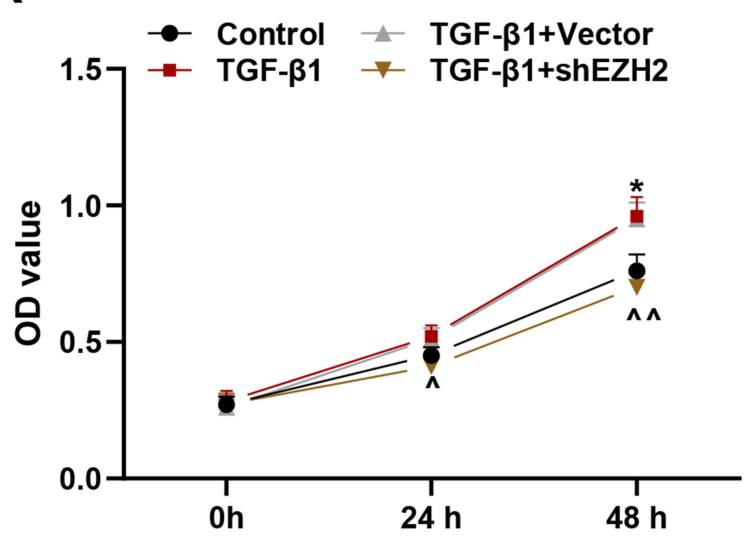

B

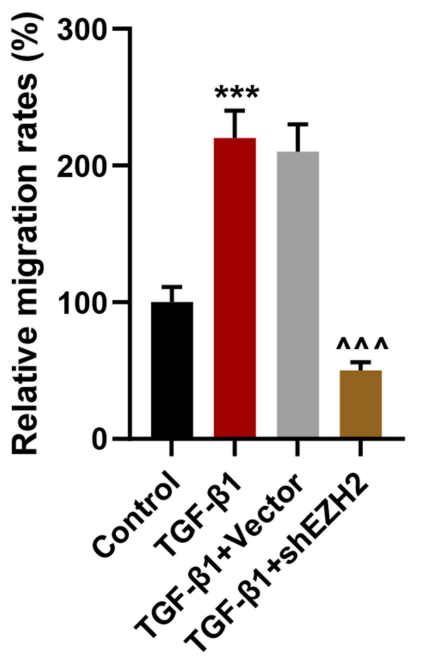

C

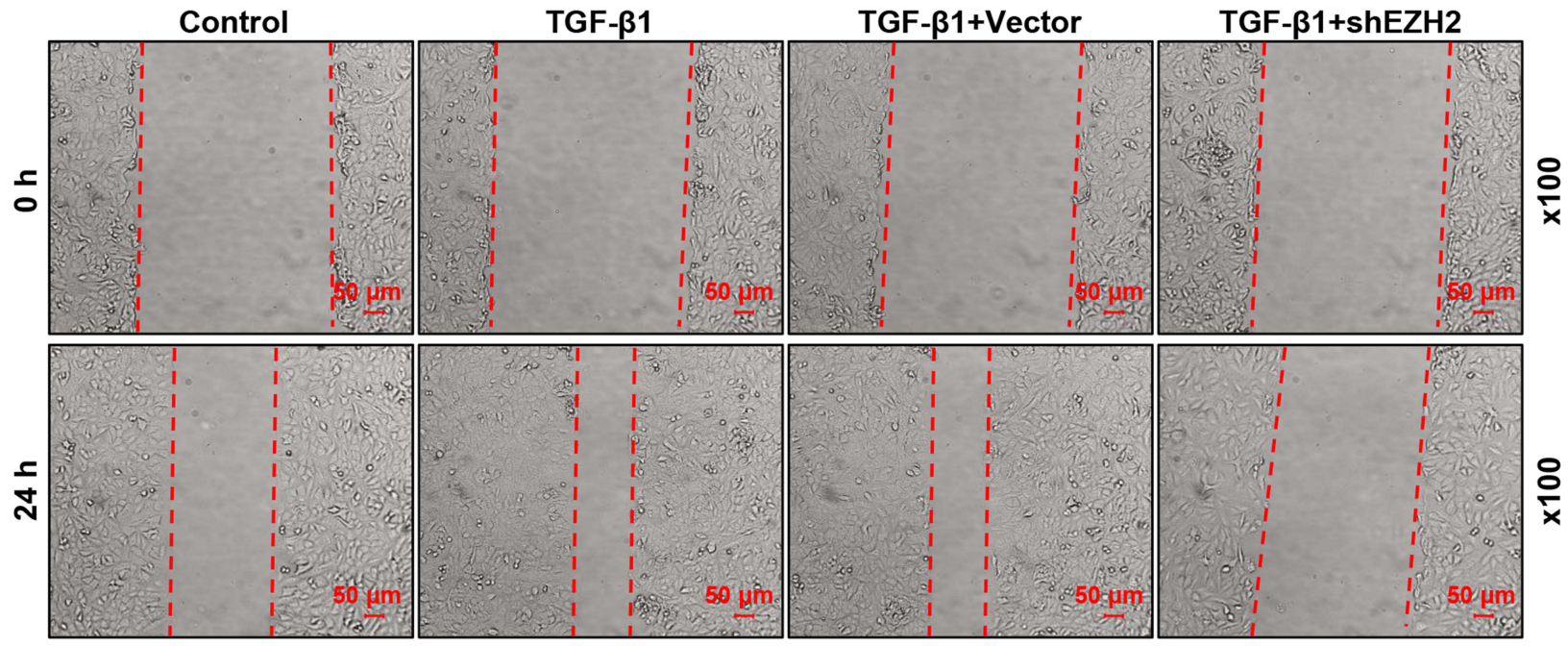

Figure 4 Silencing EZH2 reversed the effects of TGF- $\beta$ I on HCC cell viability and migration. (A) MTT assay was used to determine the viability of HCC cells following shEZH2 transfection and TGF- $\beta$ I at 0,24 and 48 hours. (B and C) Scratch assay were used to detect the migration of HCC cells at 0 and 24 hours following shEZH 2 or EZH2 overexpression plasmid transfection. Magnification: $\times 100$. All experiments have been performed in independent triplicate and data were expressed as mean \pm standard deviation (SD). $* P<0.05$, $* * * P<0.00$ I, vs Control; ${ }^{\wedge} P<0.05,{ }^{\wedge \wedge} P<0.0$ I, ${ }^{\wedge \wedge} P<0.00$ I, vs TGF- $\beta I+$ Vector.

Abbreviation: TGF- $\beta$ I, transforming growth factor- $\beta$ I. 
A

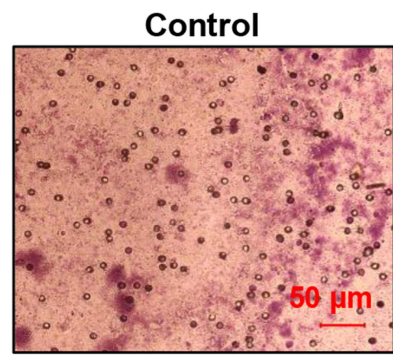

TGF- $\beta 1$

TGF- $\beta 1+$ Vector

TGF- $\beta 1+$ shEZH2

B
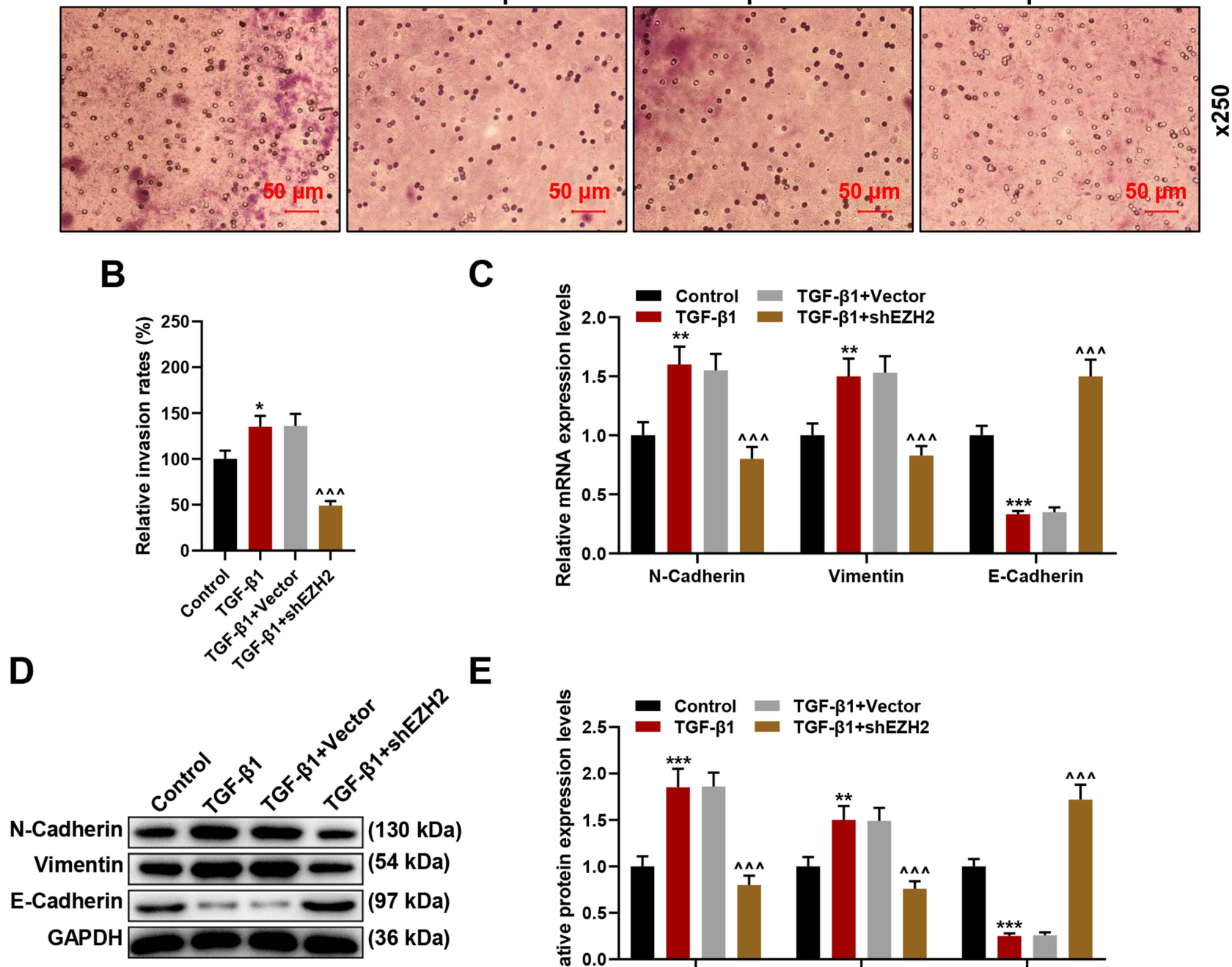

C

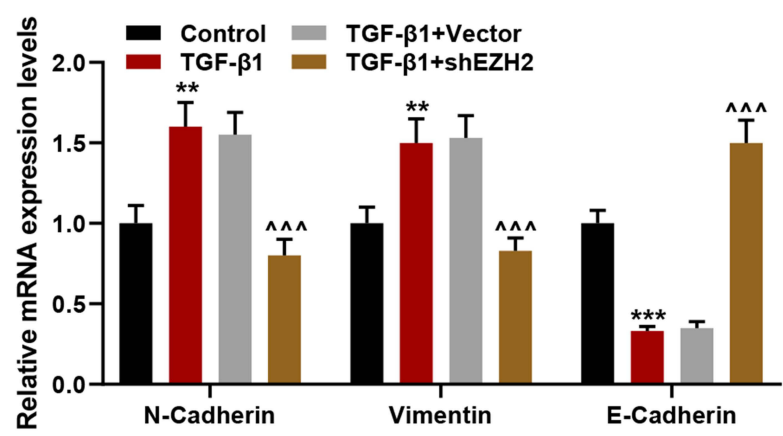

E

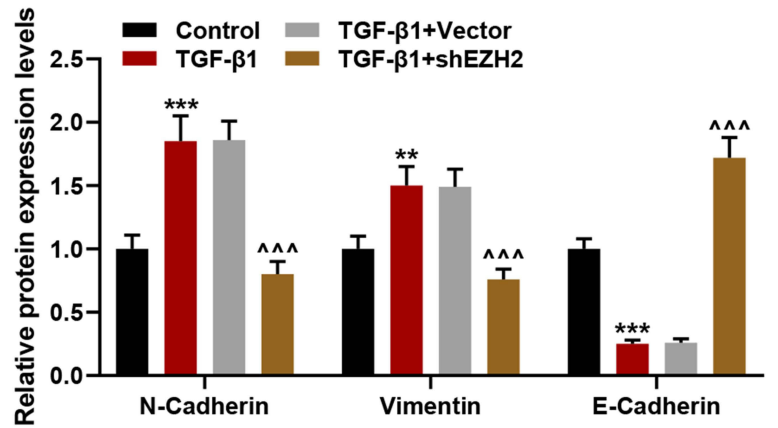

Figure 5 Silencing EZH2 reversed the effects of TGF- $\beta$ I on HCC cell invasion and epithelial-to-mesenchymal transition (EMT)-related markers' expression. (A and B) Transwell assay was used to detect invasion at 24 hours of HCC cells following shEZH 2 transfection and TGF- $\beta$ I. Magnification: $\times 250$. (C) Relative mRNA expression of migration- and invasion-related factors (N-Cadherin, Vimentin and E-Cadherin) in HCC cells following shEZH2 transfection and TGF- $\beta$ I was quantified using RT-qPCR. GAPDH was used as internal reference. (D and E) Relative mRNA expression of EMT-related factors (N-Cadherin, Vimentin and E-Cadherin) in HCC cells following shEZH 2 transfection and TGF- $\beta$ I transfection was quantified using RT-qPCR. GAPDH was used as internal reference. All experiments have been performed in independent triplicate and data were expressed as mean \pm standard deviation (SD). $* P<0.05$, $* * P<0.0$ I, $* * * P<0.00$ I, vs Control; ${ }^{\wedge \wedge} P<0.00$ I, vs TGF- $\beta I+V e c t o r$.

been discovered and discussed that silencing EZH2 could decrease cell migration and invasion, with increased E-Cadherin yet decreased N-Cadherin and Vimentin in head and neck squamous cell carcinoma (HNSCC). ${ }^{31}$ In our study, overexpressed EZH2 promoted HCC cell viability, migration and invasion, with increased N-Cadherin and Vimentin yet decreased E-Cadherin; silencing EZH2, however, exerted contrary effects, which provided another evidence on the role of $\mathrm{EZH} 2$ played in $\mathrm{HCC}$.

TGF- $\beta$-MTA1-SOX4-EZH2 signaling axis may be implicated in the mechanism to promote EMT in tumor metastasis, ${ }^{16}$ which made us wonder whether TGF- $\beta$ MTA1-SMAD7-SMAD3-SOX4-EZH2 signaling axis would have the same function. As a member of the TGF- $\beta$ family of pleiotropic cytokines, TGF- $\beta$ is a possible inducer of developmental and fibrogenic EMTs, and its aberrance and EMT are also involved in the pathogenesis of cancers. ${ }^{32,33}$ It has been additionally found that TGF- $\beta$ could induce and stimulate MTA1, a gene that plays a significant role in cancer metastasis and repressed SMAD7, which subsequently led to activation of TGF- $\beta$ pathway. ${ }^{34,35}$ SMAD7 has been shown to be an inhibitor of SMAD3, whose activation was also controlled by MTA1. ${ }^{36,37}$ SOX 4 is a member of the SOX 


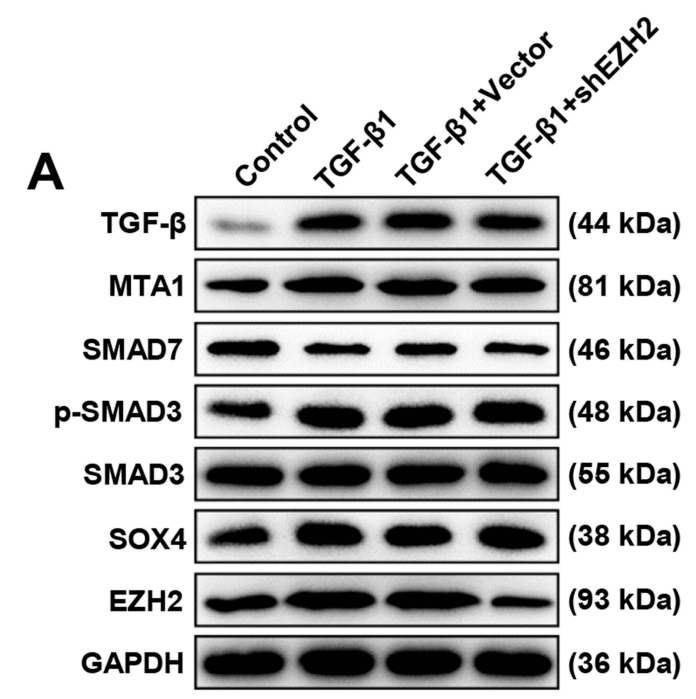

\section{B}

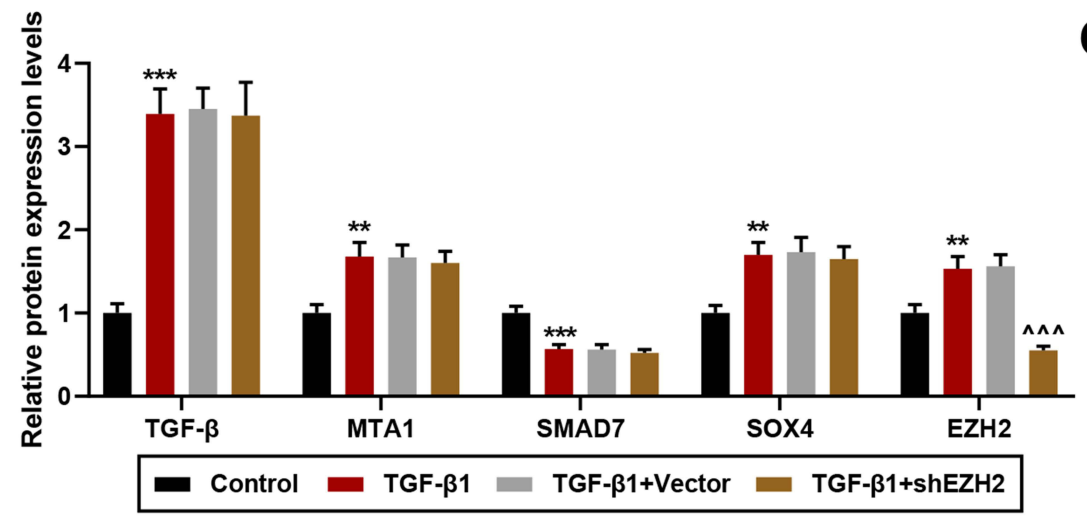

C

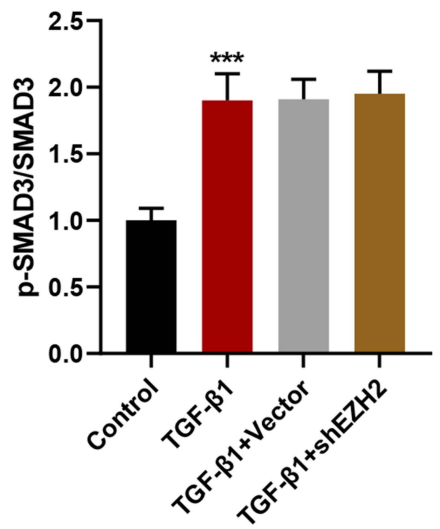

Figure 6 Silencing EZH2 solely reversed effects of TGF- $\beta$ I on EZH2 expression in TGF- $\beta$-MTAI-SMAD7-SMAD3-SOX4-EZH2 signaling axis in HCC cells. (A-C) Relative expressions of TGF- $\beta$-MTAI-SMAD7-SMAD3-SOX4-EZH2 signaling axis-related proteins were measured via Western blot, and ratios of $p$-SMAD3/SMAD3 were determined as well. GAPDH was used as internal control. All experiments have been performed in independent triplicate and data were expressed as mean \pm standard deviation (SD). **P<0.0I, ***P<0.00I, vs Control; ${ }^{\wedge \wedge} P<0.00$ I, vs TGF- $\beta 1+$ Vector.

Abbreviations: MTAI, Metastasis Associated I; SOX4, SRY-Box Transcription Factor 4; p-SMAD3, phosphorylated-SMAD3.

family which, in stem cells, is highly expressed and could interact with and be regulated by TGF- $\beta$ and its downstream molecule SMAD3.$^{38}$ Moreover, SOX4 has the capability to induce EZH2 transcription, and thus reprograms the cancer epigenome so as to promote EMT and metastasis. ${ }^{39}$ In our study, we found that following TGF- $\beta$ treatment, TGF- $\beta$, MTA1, SOX4 and EZH2 expressions and p-SMAD3/ SMAD3 ratios were increased, whereas SMAD7 was downregulated. A reversed effect on EZH2 expression solely, however, was found following silencing EZH2 in HCC cells, which further pointed out the role and effect of TGF$\beta$-MTA1-SMAD7-SMAD3-SOX4-EZH2 signaling axis in HCC.

The present study provides a crucial part for EZH2 in prognosis of HCC and theoretical basis for TGF- $\beta$ -
MTA1-SMAD7-SMAD3-SOX4-EZH2 signaling cascade in EMT of HCC cells. Inhibiting these signals may represent a therapeutic pathway for the treatment of metastatic HCC. Nevertheless, there are some limitations we wanted to address. In our study, we solely confirmed that TGF- $\beta$-MTA1-SMAD7-SMAD3-SOX4-EZH2 signaling axis may be involved in HCC cells in vitro, but whether this novel-discovered signaling axis was implicated in vivo needs to be further proved and validated. Another limitation of the study of how the signaling axis has been defined was not studied. The TGF $\beta$-MTA1SMAD7-SMAD3-SMAD3-SOX4-EZH2 axis is described, but the intermediary mediators are varied, such as other SMAD members and other SOX. In addition, transcription factors that trigger EMT and are 


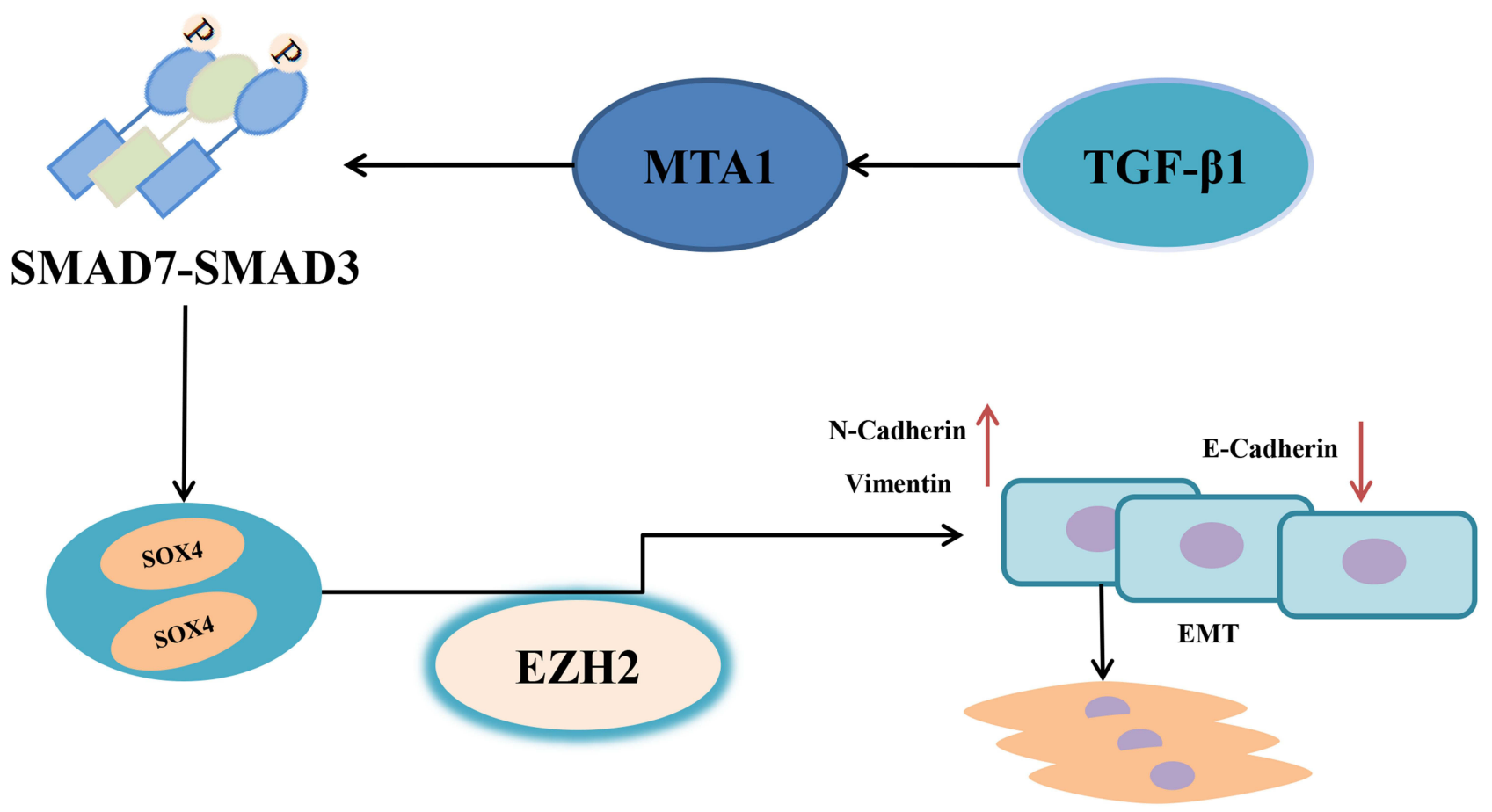

Figure 7 Schematic diagram showing the TGF- $\beta$-MTAI-SMAD7-SMAD3-SOX4-EZH2 signaling axis in promoting EMT in HCC cells.

Abbreviations: TGF- $\beta$, transforming growth factor- $\beta$; MTAI, Metastasis Associated I; SOX4, SRY-Box Transcription Factor 4; HCC, hepatocellular carcinoma; EMT, epithelial-to-mesenchymal transition.

downstream of the pathway are multiple. Therefore, future studies are needed to complete our results.

\section{Conclusion}

In our current study, we unveiled another evidence with regard to the role of EZH2 on $\mathrm{HCC}$, and its interaction with TGF- $\beta 1$, a member of TGF- $\beta$-MTA1-SMAD7-SMAD3-SOX4-EZH2 signaling axis. To be specific, EZH2 was upregulated in $\mathrm{HCC}$, and EZH2 overexpression promoted cell viability, migration and invasion, while silencing EZH2 did contrarily. Furthermore, EZH2 silence reversed the effects of TGF- $\beta 1$. These results in our study not only provide evidence on EZH2 but also propose a brand-new discovery of TGF- $\beta$-MTA1SMAD7-SMAD3-SOX4-EZH2 signaling axis in HCC, and we hope that results from our study can help gain better insights on $\mathrm{HCC}$ and possible strategy for $\mathrm{HCC}$ in the near future.

\section{Funding}

This work was supported by the National Natural Science Foundation of China [No.81471612, 81572427]; Shenzhen Key Medical Discipline Construction Fund (No. SZXK079); and Youth Fund of The Third People's Hospital of Shenzhen (No. G2021003).

\section{Disclosure}

The authors declare no conflicts of interest.

\section{References}

1. Craig AJ, von Felden J, Garcia-Lezana T, Sarcognato S, Villanueva A. Tumour evolution in hepatocellular carcinoma. Nat Rev Gastroenterol Hepatol. 2020;17(3):139-152. doi:10.1038/s41575-019-0229-4

2. Sagnelli E, Macera M, Russo A, Coppola N, Sagnelli C. Epidemiological and etiological variations in hepatocellular carcinoma. Infection. 2020;48(1):7-17. doi:10.1007/s15010-019-01 $345-\mathrm{y}$

3. Galle PR, Foerster F, Kudo M, et al. Biology and significance of alphafetoprotein in hepatocellular carcinoma. Liver Int. 2019;39(12):22142229. doi:10.1111/liv.14223

4. Jin YJ, Byun S, Han S, et al. Differential alternative splicing regulation among hepatocellular carcinoma with different risk factors. BMC Med Genomics. 2019;12:175. doi:10.1186/s12920-019-0635-z

5. Rose SC. Overview of ablative therapy for hepatocellular carcinoma. Gastroenterol Hepatol (N Y). 2019;15(9):484-487.

6. Tsilimigras DI, Bagante F, Moris D, et al. Defining the chance of cure after resection for hepatocellular carcinoma within and beyond the Barcelona clinic liver cancer guidelines: a multi-institutional analysis of 1010 patients. Surgery. 2019;166(6):967-974. doi:10.1016/j. surg.2019.08.010

7. Liu GM, Xie WX, Zhang CY, Xu JW. Identification of a four-gene metabolic signature predicting overall survival for hepatocellular carcinoma. J Cell Physiol. 2020;235(2):1624-1636. doi:10.1002/ jcp. 29081

8. Ma A, Stratikopoulos E, Park KS, et al. Discovery of a first-in-class EZH2 selective degrader. Nat Chem Biol. 2020;16(2):214-222. doi:10.1038/s41589-019-0421-4 
9. Li B, Chng WJ. EZH2 abnormalities in lymphoid malignancies: underlying mechanisms and therapeutic implications. J Hematol Oncol. 2019;12(1):118. doi:10.1186/s13045-019-0814-6

10. Duan R, Du W, Guo W. EZH2: a novel target for cancer treatment. $J$ Hematol Oncol. 2020;13(1):104. doi:10.1186/s13045-020-00937-8

11. Jones BA, Varambally S, Arend RC. Histone methyltransferase EZH2: a therapeutic target for ovarian cancer. Mol Cancer Ther. 2018;17(3):591-602. doi:10.1158/1535-7163.MCT-17-0437

12. Labbe DP, Sweeney CJ, Brown M, et al. TOP2A and EZH2 provide early detection of an aggressive prostate cancer subgroup. Clin Cancer Res. 2017;23(22):7072-7083. doi:10.1158/1078-0432.CCR17-0413

13. Zhang H, Qi J, Reyes JM, et al. Oncogenic deregulation of EZH2 as an opportunity for targeted therapy in lung cancer. Cancer Discov. 2016;6(9):1006-1021. doi:10.1158/2159-8290.CD-16-0164

14. Chen $\mathrm{S}, \mathrm{Pu}$ J, Bai J, et al. EZH2 promotes hepatocellular carcinoma progression through modulating miR-22/galectin-9 axis. J Exp Clin Cancer Res. 2018;37(1):3. doi:10.1186/s13046-017-0670-6

15. Shi Y, Yang X, Xue X, et al. HANR promotes hepatocellular carcinoma progression via miR-214/EZH2/TGF-beta axis. Biochem Biophys Res Commun. 2018;506(1):189-193. doi:10.1016/j. bbrc.2018.10.038

16. Li L, Liu J, Xue H, et al. A TGF- $\beta$-MTA1-SOX4-EZH2 signaling axis drives epithelial-mesenchymal transition in tumor metastasis Oncogene. 2020;39(10):2125-2139. doi:10.1038/s41388-019-1132-8

17. General Assembly of the World Medical Association. World medical association declaration of Helsinki: ethical principles for medical research involving human subjects. JAMA. 2013;310(20):21912194. doi:10.1001/jama.2013.281053

18. Kolosova I, Nethery D, Kern JA. Role of Smad2/3 and p38 MAP kinase in TGF-beta1-induced epithelial-mesenchymal transition of pulmonary epithelial cells. J Cell Physiol. 2011;226(5):1248-1254. doi: $10.1002 /$ jcp. 22448

19. Livak KJ, Schmittgen TD. Analysis of relative gene expression data using real-time quantitative PCR and the $2-\Delta \Delta \mathrm{CT}$ method. Methods (San Diego, Calif). 2001;25(4):402-408. doi:10.1006/ meth.2001.1262

20. Chittock EC, Latwiel S, Miller TC, Müller CW. Molecular architecture of polycomb repressive complexes. Biochem Soc Trans. 2017;45 (1):193-205. doi:10.1042/bst20160173

21. Margueron R, Reinberg D. The Polycomb complex PRC2 and its mark in life. Nature. 2011;469(7330):343-349. doi:10.1038/ nature 09784

22. Cyrus S, Burkardt D, Weaver DD, Gibson WT. PRC2-complex related dysfunction in overgrowth syndromes: a review of EZH2, EED, and SUZ12 and their syndromic phenotypes. Am J Med Genet C Semin Med Genet. 2019;181(4):519-531. doi:10.1002/ ajmg.c. 31754

23. Feitelson MA, Arzumanyan A, Kulathinal RJ, et al. Sustained proliferation in cancer: mechanisms and novel therapeutic targets. Semin Cancer Biol. 2015;35:S25-S54. doi:10.1016/j. semcancer.2015.02.006

24. Talmadge JE, Fidler IJ. AACR centennial series: the biology of cancer metastasis: historical perspective. Cancer Res. 2010;70 (14):5649-5669. doi:10.1158/0008-5472.CAN-10-1040

Cancer Management and Research

\section{Publish your work in this journal}

Cancer Management and Research is an international, peer-reviewed open access journal focusing on cancer research and the optimal use of preventative and integrated treatment interventions to achieve improved outcomes, enhanced survival and quality of life for the cancer patient.
25. Zhuang J, Huo Q, Yang F, Xie N. Perspectives on the role of histone modification in breast cancer progression and the advanced technological tools to study epigenetic determinants of metastasis. Front Genet. 2020;11:603552. doi:10.3389/fgene.2020.603552

26. Zhang J, Miller Z, Musich PR, et al. DSTYK promotes metastasis and chemoresistance via EMT in colorectal cancer. Front Pharmacol. 2020;11:1250. doi:10.3389/fphar.2020.01250

27. Xu Y, Ren H, Jiang J, et al. KIAA0247 inhibits growth, migration, invasion of non-small-cell lung cancer through regulating the Notch pathway. Cancer Sci. 2018;109(4):1055-1065. doi:10.1111/cas.13539

28. Liu X, Chu KM. E-cadherin and gastric cancer: cause, consequence, and applications. Biomed Res Int. 2014;2014:637308. doi:10.1155/ 2014/637308

29. Mrozik KM, Blaschuk OW, Cheong CM, Zannettino ACW, Vandyke $\mathrm{K}$. N-cadherin in cancer metastasis, its emerging role in haematological malignancies and potential as a therapeutic target in cancer. BMC Cancer. 2018;18(1):939. doi:10.1186/s12885-018-4845-0

30. Ivaska J. Vimentin: central hub in EMT induction? Small GTPases. 2011;2(1):51-53. doi:10.4161/sgtp.2.1.15114

31. Chang JW, Gwak SY, Shim GA, et al. EZH2 is associated with poor prognosis in head-and-neck squamous cell carcinoma via regulating the epithelial-to-mesenchymal transition and chemosensitivity. Oral Oncol. 2016;52:66-74. doi:10.1016/j.oraloncology.2015.11.002

32. Nickel J, Ten Dijke P, Mueller TD. TGF- $\beta$ family co-receptor function and signaling. Acta Biochim Biophys Sin (Shanghai). 2018;50 (1):12-36. doi:10.1093/abbs/gmx126

33. Su J, Morgani SM, David CJ, et al. TGF- $\beta$ orchestrates fibrogenic and developmental EMTs via the RAS effector RREB1. Nature. 2020;577(7791):566-571. doi:10.1038/s41586-019-1897-5

34. Sen N, Gui B, Kumar R. Role of MTA1 in cancer progression and metastasis. Cancer Metastasis Rev. 2014;33(4):879-889. doi:10.1007/s10555-014-9515-3

35. Wang T, Li W, Huang H, Wang C. Metastasis-associated 1 (MTA1) gene expression promotes angiogenesis in mouse xenografts from human non-small cell lung cancer (NSCLC) cells. Med Sci Monit. 2019;25:484-491. doi:10.12659/msm.912321

36. Chung AC, Dong Y, Yang W, Zhong X, Li R, Lan HY. Smad7 suppresses renal fibrosis via altering expression of TGF- $\beta / \mathrm{Smad} 3-$ regulated microRNAs. Mol Ther. 2013;21(2):388-398. doi:10.1038/ $\mathrm{mt} .2012 .251$

37. Salot S, Gude R. MTA1-mediated transcriptional repression of SMAD7 in breast cancer cell lines. Eur J Cancer. 2013;49(2):492499. doi:10.1016/j.ejca.2012.06.019

38. Hanieh H, Ahmed EA, Vishnubalaji R, Alajez NM. SOX4: epigenetic regulation and role in tumorigenesis. Semin Cancer Biol. 2019. doi:10.1016/j.semcancer.2019.06.022

39. Hasegawa $S$, Nagano $H$, Konno $M$, et al. A crucial epithelial to mesenchymal transition regulator, Sox $4 / E z h 2$ axis is closely related to the clinical outcome in pancreatic cancer patients. Int $J$ Oncol. 2016;48(1):145-152. doi:10.3892/ijo.2015.3258
The manuscript management system is completely online and includes a very quick and fair peer-review system, which is all easy to use. Visit http://www.dovepress.com/testimonials.php to read real quotes from published authors. 